\begin{tabular}{|l|l|l|l|l|l|}
\hline J. Tek. Ling. & Vol. 10 & No. 1 & Hal. 19 - 25 & Jakarta, Januari 2009 & ISSN 1441-318X \\
\hline
\end{tabular}

\title{
KERAGAMAN LUMUT DI RESORT KARANG RANJANG, TAMAN NASIONAL UJUNG KULON, BANTEN
}

\author{
Florentina Indah Windadri \\ Peneliti di Bidang Botani, Pusat Penelitian Biologi \\ Lembaga Ilmu Pengetahuan Indonesia
}

\begin{abstract}
Abstrct
Karang Ranjang resort is a part of Ujung Kulon National Park at Banten Province. It has two type ecosystem of forest. The coastal forest ecosystem are dominated by Pandanaceae Plant and the lowland forest ecosystem is dominated by Arecaceae. Floor of the lowland forest always covered by sea water when flooding.

The first bryophyte research in this park was been done by surrounding methode and it recorded 50 specimen numbers of mosses. The identification result of the 48 speciment numbers found 33 species. Mniomalia semilimbata is dominant species on the research areas. Two species of the mosses have endemic status, Fissidens teysmanianum as endemic species in Java and Calymperes cougiense found abundant in the Malesia region and endemic in Polynesia
\end{abstract}

Key word: Ujung Kulon National Park, Karang Ranjang, Mosses, diversity, ecosystem

\section{PENDAHULUAN}

Taman Nasional Ujung Kulon merupakan salah satu kawasan konservasi di Indonesia yang berperan penting dalam menjaga kelestarian sumber daya hayati dan keseimbangan ekosistem. Kawasan ini resmi ditetapkan sebagai Taman Nasional pada tahun 1992. Luas areanya 120.551 ha, terdiri dari 76.214 ha berupa daratan dan 44.337 ha lautan ${ }^{1)}$. Tipe ekosistem di kawasan Taman Nasional ini terbagi menjadi tiga yaitu ekosistem perairan laut, pantai, dan daratan. Pada ekosistem daratan dapat ditemukan ekosistem hutan hujan tropis dataran rendah yang terluas di Jawa Barat. Keanekaragaman jenis flora phanerogamnya telah terdata dengan baik dan dilaporkan sekitar 700 jenis, 57 jenis diantaranya merupakan tumbuhan langka ${ }^{2)}$.
Namun tidak demikian halnya dengan penelitian kekayaan keanekaragaman lumutnya yang sampai saat ini masih relatif sedikit.

Penelitian keanekaragaman lumut di beberapa daerah di Indonesia telah dilakukan antara lain di Sulawesi tercatat 106 jenis $^{3)}$, dan di Borneo dilaporkan 607 jenis $^{4}$. Disamping itu beberapa pulau yang termasuk dalam kawasan kepulauan Sunda Kelapa pernah juga dilaporkan jumlah lumut daunnya yaitu di Bali tercatat 169 jenis, Lombok 152 jenis, Sumbawa 44 jenis, Flores 278 jenis, dan Timor 46 jenis $^{5)}$. Sedangkan keragaman lumut daun (Musci) di Bogor dan sekitaranya pernah dilaporkan oleh Fleischer ${ }^{6}$ ) berjumlah 452 jenis. Dalam 
rangka pembuatan taman lumut di Kebun Raya Cibodas telah dilakukan eksplorasi di beberapa tempat di Jawa Barat seperti G. Gede Pangerango, G. Salak, G. GeulisCianjur, dan beberapa tempat lain seperti G. Slamet di Jawa Tengah, Jambi dan Kalimantan. Jumlah yang telah dikoleksi dan tersedia untuk ditanam di kebun koleksi lumut sebanyak 235 jenis $^{7)}$. Keragaman lumut di Taman Nasional Ujung kulon hingga saat ini belum pernah dilakukan pendataannya. Hal ini didasarkan hasil pengecekan specimen koleksi herbarium di Herbarium Bogoriense yang tidak pernah ditemukan spesimennya. Begitu pula penelusuran pustaka terkait juga tidak pernah diketahui laporannya. Oleh karena itu perlu dilakukan penelitian khususnya tentang keanekaragaman lumut di kawasan ini dengan harapan bahwa hasil yang diperoleh akan dapat memberikan data dan informasi sebagian dari keanekaragaman lumut di Taman Nasional Ujung Kulon serta menambah kekayaan flora di Indonesia khususnya kelompok tumbuhan rendah (kriptogam).

\section{BAHAN DAN METODE}

Pendataan keragaman lumut di Resort Karang Ranjang, Taman Nasional Ujung Kulon dilakukan pada bulan Mei hingga Juni 2006. Pemilihan lokasi penelitian ini didasarkan bahwa wilayah Resort Karang Rajang mudah dijangkau (mengingat waktu penelitian yang terbatas). Lokasi penelitian ini terletak di daratan yang berbentuk leher tampak seolah-olah menyerupai penghubung antara dua pulau, serta mempunyai dua tipe hutan yaitu hutan dataran rendah dan hutan pantai. Adapun kawasan hutan yang dijelajahi antara lain hutan Tereleng, Karang Ranjang, Cisimping, Pangorok, dan Ciseuseupan.

Metode yang digunakan dalam penelitian ini adalah metode jelajah ${ }^{8)}$, yaitu menjelajahi seluruh area hutan baik hutan pantai maupun hutan dataran rendahnya.
Setiap kelompok lumut yang dijumpai diamati, dicatat dan diambil contoh herbariumya untuk keperluan identifikasi. Pengambilan contoh koleksi dilakukan dengan menyayat koloni lumut berikut substratnya, kemudian di masukkan dalam amplop kertas. Data lain yang perlu dicatat antara lain habitat dan substrat untuk pertumbuhannya. Pengeringan spesimen dilakukan dengan cara membuka amplopnya. Spesimen yang sudah kering angin dimasukkan kembali dalam amplop, siap untuk di pak. Identifikasi dilakukan di Herbarium Bogoriense dengan menggunakan mikroskop dan beberapa buku acuan seperti 'Die Musci der Flora von Buitenzorg6), 'A Handbook of Malesia Mosses'9-11), 'Mosses of The Philippines'12), 'Mosses and Liverworts of Hong Kong'13). Spesimen yang sudah teridentifikasi kemudian diproses sebagai koleksi herbarium untuk menambah jumlah koleksi di Herbarium Bogoriense.

\section{HASIL DAN PEMBAHASAN}

\subsection{Keadaan umum lokasi penelitian}

Pada pengamatan di lokasi penelitian dapat dilaporkan bahwa hutan dataran rendah di Resort Karang Ranjang mempunyai topografi datar (Cisimping) hingga agak berbukit (Ciseuseupan dan Pengorok). Vegetasi hutan yang bertopografi datar didominasi oleh kelompok suku Arecaceae khususnya pohon langkap (Arenga obtusifolia) dan rotan (Daemonorops spp \& Calamus spp). Sedangkan lantai hutannya sebagian besar berawa dan tidak ditemukan tumbuhan (semak-semak). Keadaan lantai hutan seperti ini terjadi disebabkan oleh beberapa hal diantaranya akibat selalu terkena oleh pasang surutnya air laut sehingga biji-biji yang jatuh ke tanah terbawa hanyut oleh air pasang-surut tersebut. Selain itu juga dapat disebabkan oleh rapatnya populasi langkap sehingga cahaya matahari tidak dapat menembus kerapatan kanopi pohonpohon palem dan biji-biji yang masih 
terdapat di lantai hutan tidak berkecambah, hal ini akan berakibat rendahnya regenerasi hutan. Perkecambahan biji di hutan akan terjadi secara cepat jika pada kondisi lingkungan terbuka dengan kekeringan tanah sedang ${ }^{14)}$. Meskipun kondisi lingkungannya demikian, masih dapat ditemukan tumbuhan epifit yang mampu tumbuh yaitu kelompok tumbuhan lumut. Lumut ditemukan tumbuh di batang-batang pohon, sedangkan di lantai hutannya yang selalu tergenang air tidak ditemukan pertumbuhan lumut. Menurut Richardson ${ }^{15}$ ) dan Richards ${ }^{16)}$, perkecambah-an spora, pertumbuhan dan perkembangan tumbuhan lumut dipengaruhi oleh beberapa faktor diantaranya kelembaban dan intensitas sinar matahari. Rais, dkk ${ }^{17)}$ melaporkan bahwa kelembaban di kawasan taman nasional ini berkisar 80-90\%. Di hutan pantai (Tereleng dan Karang Ranjang) umumnya mempunyai kondisi lingkungan terbuka, panas dan kering, kondisi ini sangat berlawanan dengan hutan dataran rendah yang diteliti. Berdasarkan laporan Rais, $\mathrm{dkk}^{17)}$ bahwa suhu di kawasan taman nasional ini berkisar $25^{\circ}-30^{\circ} \mathrm{C}$. Tumbuhan yang mendominasinya termasuk dalam suku Pandanaceae. Dua jenis anggota suku Pandanaceae yang ditemukan adalah pandan (Pandanus tectorius) paling banyak dan bidur (Pandanus dubius) tumbuh hanya pada satu tempat di tepi pantai. Di bagian yang agak jauh dari pantai ditemukan beberapa pohon jambu kopo laut (Syzygium pseudoformosum), Baringtonia asiatica, dan semak-semak dari marga Etlingera di lantai hutannya. Dengan kondisi lingkungan yang demikian maka lumut di hutan pantai ini jarang ditemukan. Beberapa jenis lumut yang ditemukan umumnya tumbuh di batang-batang pohon atau perakaran pandan yang lembab. Sedangkan di lantai hutannya jarang ditemukan.

\subsection{Keanekaragaman lumut di lokasi penelitian}

Hasil penelitian di lima hutan yang dijelajahi telah mengumpulkan 50 nomor koleksi lumut daundan teridentifikasi menjadi 33 jenis (Tabel 1.)

Tabel 1. Keragaman Jenis Lumut Daun di Hutan Resort Karang Ranjang TN. Ujung Kulon, Banten

\begin{tabular}{|c|c|c|c|c|c|c|c|}
\hline \multirow{2}{*}{ Ilo } & \multirow{2}{*}{ llama suku / jenis } & \multicolumn{5}{|c|}{$\begin{array}{l}\text { Lokasi eksplor asi dan } \\
\text { koleksi }\end{array}$} & \multirow{2}{*}{ Habitat } \\
\hline & & T & TI & TII & TV & V & \\
\hline 1. & $\begin{array}{l}\text { BRYACEAE: } \\
\text { Bryum trewbii Broth. }\end{array}$ & - & - & + & - & - & Batang Arenga obtusifoila \\
\hline 2. & Epipterygium tozen Linds. & - & - & + & - & - & Batang Arenga obtusifoina \\
\hline 3. & $\begin{array}{l}\text { CALYWPERACEAE: } \\
\text { Calymperes cougiense Besch. }\end{array}$ & - & - & + & + & - & Batang Pancianus tectomius \\
\hline 4. & $\begin{array}{l}\text { Calymperes crassinerve (witt.) } \\
\text { Jaeg. }\end{array}$ & - & + & - & - & - & Akar Pandanus dubius \\
\hline 5. & Calymperes erosum C. Mull. & + & - & + & - & - & $\begin{array}{l}\text { Batangsyzyoum } \\
\text { pseudoformosum }\end{array}$ \\
\hline 6. & $\begin{array}{l}\text { Calymperes moliccense } \\
\text { Schwaegr. }\end{array}$ & - & - & - & - & + & Batang Baringtonia asiatica \\
\hline 7. & Calymperes palisotï Schwaegr. & - & - & + & - & - & Batang Oncosperma boginana \\
\hline 8. & Calymperes schmidin Eroth. & - & - & + & - & - & $\begin{array}{l}\text { Batang Arenga obtusifoila \& } \\
\text { kibatok }\end{array}$ \\
\hline 9. & $\begin{array}{l}\text { Lewcophanes glawcwm } \\
\text { (Schwaegr.) witt. }\end{array}$ & - & - & + & - & - & Batang kitokeh \\
\hline 10. & $\begin{array}{l}\text { Syrhopodon albovaginatus } \\
\text { Schwaegr. }\end{array}$ & - & - & - & + & - & Batang Arenga obtusifowa \\
\hline 11. & $\begin{array}{l}\text { Syrmopodon polifer Schwaegr. } \\
\text { var laevis (Dix.) A. Eddy }\end{array}$ & - & - & + & - & - & Batang Arenga obtusifoia \\
\hline
\end{tabular}




\begin{tabular}{|c|c|c|c|c|c|c|c|}
\hline 13. & $\begin{array}{l}\text { Syrrhopodon involutus } \\
\text { Schwaegr. }\end{array}$ & - & - & + & - & - & Batang Oncosperma bgginana \\
\hline 14. & $\begin{array}{l}\text { Syrhopodon semilmber(mitt.) } \\
\text { Besch. }\end{array}$ & - & - & - & - & + & Batang Baringtonia asiatica \\
\hline 15. & Syrrhopodon trachyphyllus wont. & - & + & - & - & - & Eatang Pandanus dubius \\
\hline 16. & $\begin{array}{l}\text { FISSIDENTACEAE:: } \\
\text { Fisidens areolatus Giff. }\end{array}$ & - & - & + & - & - & Batang Arenga obtusifolia \\
\hline 17. & $\begin{array}{l}\text { Fissidens brauni (C.Mull.) Doz. \& } \\
\text { Molk. }\end{array}$ & - & - & + & + & - & $\begin{array}{l}\text { Batang Arenga obxusifolia, } \\
\text { Anacolo-sa frutescens }\end{array}$ \\
\hline 18. & $\begin{array}{l}\text { Fis sidens perpucilusWils. ex } \\
\text { Mitt. }\end{array}$ & - & + & - & - & - & Batang Kleinhovia hospkia \\
\hline 19. & $\begin{array}{l}\text { Fissidens teysmanianum Doz. \& } \\
\text { Molk. }\end{array}$ & - & - & + & - & - & Batang Pandamus fixcatus \\
\hline 20. & $\begin{array}{l}\text { HOOKER } \mathrm{ACEAE}:: \\
\text { Chaetomitrum lanceolatum Lac. }\end{array}$ & - & - & + & - & - & Batang oncosperma tiggiliaria \\
\hline 21. & $\begin{array}{l}\text { HYPNACEAE: } \\
\text { Ectropothecium sp. }\end{array}$ & - & - & - & + & - & Batu karang \\
\hline 22 . & $\begin{array}{l}\text { Ectropothecium dealbatum } \\
\text { (Hornsch.\& Reirm.) Jaeg. }\end{array}$ & - & + & - & + & - & $\begin{array}{l}\text { Batang Diosyros caulifora, } \\
\text { Pterospermum diversifolium, } \\
\text { kayu lapuk }\end{array}$ \\
\hline 23. & $\begin{array}{l}\text { (sopterygim albescens } \\
\text { (Schmaegr.) Jaeg. }\end{array}$ & - & - & + & - & - & Batang Arenga obtusifolia \\
\hline 24. & $\begin{array}{l}\text { Isopterygium bancanum(Lac) } \\
\text { Jaeg. }\end{array}$ & - & - & - & + & - & Kayulapuk \\
\hline 25. & $\begin{array}{l}\text { Isopterygium minutíameum(C. } \\
\text { Mull.) Jaeg. }\end{array}$ & - & - & - & + & - & Akar Pandanus tectonus \\
\hline 26. & isopterygium saxense Willams & - & + & - & - & - & Batang Diospyros caulifiora \\
\hline 27 . & $\begin{array}{l}\text { Vesicwana dubyana (C. Mull.) } \\
\text { Broth. }\end{array}$ & - & - & - & - & + & Kayulapuk \\
\hline 28. & $\begin{array}{l}\text { Vesicuana montagnei(Bel.) } \\
\text { Fleisch. }\end{array}$ & - & - & - & + & - & Batang Pandanus furcatus \\
\hline 29. & $\begin{array}{l}\text { Vesicwana montagnei(Bel.) } \\
\text { Fleisch. }\end{array}$ & - & - & - & + & - & Batang Pandamus furcatus \\
\hline 30. & $\begin{array}{l}\text { PHYLLODREPANIACEAE: } \\
\text { Mniomalia semilmbata (Mitt.) C. } \\
\text { Mull. }\end{array}$ & - & - & + & + & - & $\begin{array}{l}\text { Batang Arenga obtusifolia dan } \\
\text { Kayu lapuk }\end{array}$ \\
\hline 31. & $\begin{array}{l}\text { SEMATOPHYYLACEAE: } \\
\text { Sematophyimm sp. }\end{array}$ & - & + & - & - & - & Kayu lapuk \\
\hline 32. & $\begin{array}{l}\text { Sematophylim microcladioides } \\
\text { Broth. }\end{array}$ & - & - & + & - & - & Batang Arenga obtusifois \\
\hline 33. & $\begin{array}{l}\text { Sematophymum tristiculum(mitt.) } \\
\text { Fleisch. }\end{array}$ & - & - & - & + & + & Kayulapuk \\
\hline 34. & $\begin{array}{l}\text { Wandugiella cupressinoides C. } \\
\text { Mull. }\end{array}$ & - & + & - & - & - & Kayulapuk \\
\hline 35. & $\begin{array}{l}\text { THUIDIACEAE: } \\
\text { Thuidum kirsense Williams }\end{array}$ & - & - & - & + & - & Akar Pandamus tectomus \\
\hline 36. & Thuidum tamariscellum C. Mull. & - & - & - & + & + & $\begin{array}{l}\text { Batang Ficus anmuata, batu } \\
\text { karang }\end{array}$ \\
\hline
\end{tabular}

Keterangan: Lokasi
I: Tereleng
II : Karang Ranjang
III : Cisimping
IV : Pengorok
$V$ : Ciseuseupan
+ : ditemukan
- : tidak ditemukan 
Berdasarkan Tabel 1. tampak bahwa lumut yang dominant di lokasi penelitian adalah kelompok suku Calymperaceae (ada 13 jenis). Kehadirannya dilokasi penelitian cukup banyak (sekitar 37\%) karena anggota dari suku ini mempunyai kisaran habitat cukup luas dan cara perbanyakan yang bervariasi. Selain menggunakan spora yang dihasilkan oleh generasi sporofit, perbanyakannya juga dapat dilakukan secara vegetatif dengan menggunakan kuncup (gemmma) yang terdapat pada ujung-ujung pertulangan daunnya. Kuncupkuncup tersebut apabila terlepas dan menemukan lingkungan yang cocok akan tumbuh sebagai individu baru ${ }^{18)}$ Selain itu bentuk pertumbuhannya yang mengelompok menyerupai batalan seperti pada marga Syrrhopodon memungkinkan lumut dapat mempertahankan keberadaan air di lingkung-annya sehingga jika terjadi kekeringan masih dapat bertahan hidup.

Apabila dilihat dari keragaman jenis lumut di masing-masing lokasi pengamatan maka keragaman jenis lumut terbanyak ditemukan di lokasi III (Cisimping) yang tumbuh pada substrat berupa batang pohon. Kondisi lingkungan yang lembab di lokasi ini cukup mendukung untuk perkecambahan spora, pertumbuhan dan perkembangan lumut terutama di batang pohon. Namun tidak demikian halnya dengan lumut-lumut yang bersubstrat tanah atau batuan di lantai hutannya. Adanya pasang surut air laut yang selalu menggenangi lantai hutan di lokasi penelitian ini juga berpengaruh terhadap spora-spora lumut yang terlepas dari kapsulnya (kotak spora). Oleh karena ukurannya sangat kecil dan ringan maka akan mudah hanyut terbawa air pasang surut, sehingga tidak akan mungkin dapat tumbuh di lantai hutan dengan keadaan demikian pada lantai hutan di lokasi penelitian ini tidak dijumpai tumbuhan lumut. Adapun jenis-jenis lumut yang ditemukan di lokasi ini antara lain Bryum treubii, Calymperes geppii, Ectropothecium dealbatum, Epipterygium tozeri, Fissidens braunii, Fissidens areolatus, Mniomalia semilimbata, Semathophyllum microcladioides, Syrrhopodon albovaginatus, Syrrhopodon prolifer var. Laevis, dan Isopterygium albescens tumbuh di batang pohon langkap. Keadaan sebaliknya terjadi di lokasi I (Tereleng) dengan kondisi lingkungan panas dan kering. Lumut yang ditemukan di lokasi ini hanya satu jenis yaitu Calymperes erosum yang tumbuh di batang pohon Syzygium pseudorantemum. Dengan ditemukannya Calymperes erosum pada habitat seperti ini menunjukkan bahwa lumut ini mempunyai toleransi terhadap suhu yang relatif panas dan mempunyai daya tahan terhadap kekeringan lebih baik dibandingkan dengan jenis-jenis lumut lainnya. Hal ini didukung oleh laporan Eddy ${ }^{10)}$ dan Ellis \& $\operatorname{Tan}^{19)}$ yang menyatakan bahwa Calymperes erosum mampu tumbuh pada kondisi lingkungan terbuka maupun teduh, pada berbagai substrat seperti pohon mulai dari perakaran hingga rantingnya serta di bebatuan maupun tanah lembab pada ketinggian mencapai $500 \mathrm{~m}$ di atas permukaan laut.

Selain bersubstrat batang-batang pohon beberapa jenis lumut di lokasi penelitian juga ada yang bersubstrat kayu-kayu lapuk ataupun batu karang. Kayu lapuk merupakan media yang baik bagi lumut karena kayunya yang telah mengalami pelapukan mampu menyerap dan menyimpan air cukup banyak di antara selsel kayunya. Demikian juga halnya dengan batu-batu karang yang berada ditepi laut juga mempunyai permukaan kasar yang memungkinkan dapat menampung air di celah-celah atau cekungan batunya. Keadaan seperti ini dapat membuat lingkungannya menjadi lembab. Dengan demikian maka spora lumut yang jatuh pada kedua substrat tersebut serta didukung oleh intensitas sinar yang cukup dapat berkecambah, tumbuh dan berkembang menjadi tumbuhan lumut. Di lokasi penelitian ditemukan 6 jenis lumut yang bersubstrat kayu lapuk yaitu Sematophyllum tristiculum, Warburgiella cupressinoides, Mniomalia semilimbata, Vesicula dubyana, 
Isopterygium bancanum, dan Syrrhopodon spiculosus. Sedangkan lumut yang bersubstrat batu karang ada 2 jenis yaitu Thuidium tamaricellum dan Ectropothecium sp.

Beberapa jenis lumut seperti: Mniomalia semilimbata, Fissidens teysmanianum, Calymperes cougiense, dan Calymperes palisotii yang ditemukan di lokasi peneli-tian mempunyai catatan penting ditinjau dari sisi taksonominya. Mniomalia semilimbata disebutkan sebagai satu-satunya jenis dari anggota suku Phyllodrepaniaceae yang ditempatkan mendekati suku Mniaceae atau Rhizogoniaceae ${ }^{11}$. Jenis ini di lokasi penelitian ditemukan cukup melimpah di beberapa tempat. Selain di Jawa jenis ini juga pernah ditemukan di Irian Jaya dan Sumatra bagian timur. Fissidens teysmanianum merupakan lumut akrokarpus (tumbuh tegak) yang soliter di tempat terbuka, jenis ini dilaporkan endemik di Jawa ${ }^{9}$. Calymperes cougiense banyak tumbuh di hutan dataran rendah dekat pantai dengan kondisi lingkungan agak terbuka dan dilaporkan sebagai satu jenis lumut yang tumbuh hanya di kawasan Polinesia dan melimpah di kawasan Malesia ${ }^{(10)}$. Sedangkan Calymperes palisotii menurut Fleischer ${ }^{6}$ dan Eddy ${ }^{\left({ }^{(10}\right)}$ merupakan jenis lumut yang tumbuh di daerah tropis terutama di Afrika dan Amerika, namun di kawasan Malesia jenis ini hanya ditemukan di beberapa tempat di Jawa dengan sebutan Calymperes geppii

\section{KESIMPULAN}

Kemelimpahan lumut sangat dipengaruhi oleh keragaman alat reproduksi yang dimiliki dan bentuk kehidupannya. Selain fak-tor kelembaban dan intensitas cahaya, kondisi lingkungan seperti pasang surutnya air laut juga berpengaruh terhadap keberadaan lumut di lantai hutannya.

Hasil pendataan lumut daun di lokasi penelitian tercatat sebanyak 33 jenis yang tumbuh pada substat berupa batang pohon, kayu lapuk dan batu karang. Sebanyak 4 jenis lumut yang ditemukan mempunyai catatan penting dari sisi taksonomi dan 2 jenis diantaranya merupakan jenis endemik.

\section{DAFTAR PUSTAKA}

1. Maulana, H., L. Sari, dan A.N. Susdihanto. 2004, Menjelajah Situs Alam warisan Dunia Taman Nasional Ujung Kulon, Balai Taman Nasional Ujung Kulon

2. Sriyanto, A., D. Suganda, E. Widjanarti, D. Sutaryono, A. Hermawan, dan G. Suharyanto (Eds.), 2003, Buku Panduan 41 Taman Nasional di Indonesia, Departemen Kehutanan Republik Indonesia, UNESCO dan CIFOR

3. Dixon,N.H. 1939, Moss of Celebes, Dalam Annales Bryologici V (7):1936

4. Touw, A. 1978, The Mosses reported from Borneo, Dalam Journ. Hattori Bot. Lab. 44: 147-176

5. Touw, A. 1992, A Survey of The Mosses of The Lesser Sunda Islands (Nusa Teng-gara) Indonesia, Dalam Journ. Hattori Bot. Lab. 71: 289-366.

6. Fleischer.M. 1900-1908, Die Musci der Flora von Buitenzorg , Buchhandlung und Druckerei vormals E.J. Brill, Leiden, vol.1-3 : 1103 halaman.

7. Damayanti, L. 2006, Koleksi Bryophyta Taman Lumut Kebun Raya Cibodas. UPT Balai Konservasi Tumbuhan Kebun Raya Cibodas, Sindanglaya, Cianjur. 81 halaman.

8. Rugayah, A. Retnowati, F.I. Windadri, dan A. Hidayat, 2004, Pengumpulan data Taksonomi. Dalam Rugayah, E.A. Widjaja, dan Praptiwi (Eds.), Pedoman Pengumpulan Data Keanekaragaman Flora, Pusat 
Penelitian Biologi, Lembaga IImu Pengetahuan Indonesia.

9. Eddy, A. 1988, A Handbook of Malesian Mosses, Natural History Museum Publi-cations London, vol.1: 204 halaman

10. Eddy, A. 1990, A Handbook of Malesian Mosses, Natural History Museum Publi-cations London, vol. $2: 256$ halaman

11. Eddy, A. 1996, A Handbook of Malesian Mosses, Natural History Museum Publications London, vol.3 : 277 halaman

12. Bartram, E.B. 1939, Mosses of The Philippines, The Philippine Journal of Science 68 (1) : 1-437

13. So.,M.L. 1995, Mosses and Liverworts of Hongkong, Heavenly People Depot. Hongkong, Vol.1: 162 halaman.

14. Hommel, P.W.F.M. 1987, Landscape ecology of Ujung Kulon (West Java, Indonesia), Privately published by Patrick W. F. M. Hommel, Wageningen.
15. Richardson, D.H.S.1981, The Biology of Mosses, Backwell Scientific Publications, Oxford, London, Edinburgh, Boston Melbourne, 220 halaman

16. Richards, P.W. 1984, The Ecology of Tro-pical Forest Bryophyte, Dalam Schuster R.M. (ed.), Manual of Bryology, Nichi-nan. volume 2

17. Rais, S, Y. Ruchiat, A. Sartono, dan T. Hideta 2007, 50 Taman Nasional di Indonesia, Departeman Kehutanan Republik Indonesia, 291 halaman (7885)

18. Yamaguchi, T., F.I. Windadri, I. Haerida, H. Simbolon, A. Kunimura, H. Miyawaki, dan H. Shimizu. 2005, Effect of Forest Fires on Bryophyte Flora in East Kalimantan, Indonesia, Dalam Phyton Annales Rei Botanica 45(4): 561-567.

19. Ellis, L.T. and B.C. Tan, 1999, The Moss family Calymperaceae (Musci) in the Philippines. In Bull. Nat. His. Mus. Lond. (Bot.) 29 (1):1-46. 